\title{
PER-CUTANEOUS FNA BIOPSY WITH OPEN LYMPH NODE BIOPSY
}

\author{
DR. QAISER MAHMOOD \\ DCP, FCPS (Medicine), \\ Assistant Professor of Medicine \\ Nishtar Hospital, Multan. \\ DR. NASREEN SIDDIQUE, \\ MCPS, M.Sc. (Community Health \& Nutrition) \\ FCPS (Community Medicine), \\ Nishtar Hospital, Multan.
}

\author{
DR. AHMED UAZ MASOOD, \\ FCPS (Radiotherapy), \\ Assistant Professor of Radiology \\ Nishtar Medical College, Multan
}

\begin{abstract}
Objective: To compare the efficacy of per cutaneous FNA biopsy with open lymph node biopsy. Setting: Nishtar Hospital, Multan. Sample size: 50 patients. Duration: One year. Results: Maximum numberof cases 35 (70\%) were between the ages of 11-40 years. During this procedure adequate specimens were obtained from all cases for cytological interpretation and no complication was observed. Benign result in 30 cases while malignant disease was observed in 19 cases and an unsatisfactory result was observed in one case. Results of this study showed that tuberculosis is still a common disease in our population. Overall accuracy of FNAB cytology was $98 \%$ on comparison with histological diagnosis indicating the usefulness of this technique. Conclusion: FNAB-C may be performed by clinician, pathologist or radiologist as an outpatient procedure. So along with other advantages it brings a new dimension of cooperation between the medical specialist, cytopathologist and radiologist in this era of emphasis on ambulatory care.
\end{abstract}

Key words: FNAB-C, Cytological interpretation, histological diagnosis.

INTRODUCTION

Fine needle aspiration biopsy (FNAB) in simple words is "aspiration by fine needle". North American workers used the designation "fine needle 
aspiration or fine needle aspiration cytology" (FNAC), for both the art and operative procedure and also sometimes for the product. Thomson prefers the term, "Thin needle selective sampling"1, while Trott 2 makes a case for calling the products aspirates or samples. Since the technique involves not simply aspiration but the collection of fine core microbiopsy, so it is commonly accepted as "Fine needle aspiration biopsy".

Fine needle aspiration biopsy with or without ultrasound guidance is used for lymph nodes, tumours of the breast, thyroid, pancreas, head and neck masses, salivary glands, lungs, mediastinum, chest wall pleura, retroperitoneal masses, liver, spleen, male and female genital organs and supporting tissue.

Kun in 1847 may have been the first to report the use of aspiration biopsy ${ }^{3}$. Griege and Gray repeated the use of needle aspiration of lymph nodes to confirm the presence of trypanosomiasis ${ }^{4}$.

During the first quarter of 20th century controversy ranged over the diagnosis of cancer by means of cell spreads rather than tissue section. Aspiration biopsy achieved little or no acceptance during this period.

Lyden $^{5}$ and Mentier6 employed needles to obtain cell tissue, fragments, the formerto isolate pneumonic microorganisms and later to diagnose pulmonary carcinoma. A few early pathologists were however, involved in the pioneering work.

In 1921, Guthie7 compiled one of the earliest series on aspiration biopsy from cervical lymphadenopathy, describing cell specimens from lymphadenitis, metastatic carcinoma and Hodgkin's diseases.

Forkner in 1927 studied node puncture from thirty patients8. In Great Britain Dudgenon and Patrick in
1927 proposed the needling of tumours as mean of rapid microscopic diagnosis?

In 1930s, the first of several reports from Memorial Centre for cancer and allied diseases appeared describing the diagnosis of tumour by needle puncture and aspiration ${ }^{10}$.

Similarly Martin and Ellis in 1934 at Memorial Hospital in USA also advocates about needle aspiration 11. Consequently they used needles of thicker caliber (18-G) than those used commonly today. This technique in Memorial Hospital of America remained an oasis but limited interest was shown by other cancer centres.

In Europe and particularly Scandinavian the fine needle aspiration as a technique began to flourish in 1950s and 1960s. Soderstrom in 198012, Frazen et al13 in Sweden and Cardozo in Holland, all clinicians/haematologists by training, became major proponents.

Zajick was among the first pathologist to embrace fine needle aspiration in collaboration with Frazen at the Karalinska Hospital to determine diagnostic accuracy in number of conditions ${ }^{14}$. Disciples of these have spread the gospel to Europe, the UK, the America, Japan and Australia.

The development of needle aspiration cytology along with exfoliative cytology was to large extent, performed by professional hybrids12. Various studies have been done on sensitivity and specificity of FNAB. The sensitivity of FNAB varies from $77 \%$ to $97.2 \%{ }^{15}$.

In one study, 48 patients of histologically proven tuberculous lymphadenitis were subjected to FNAB, 37(77\%) were detected by this technique ${ }^{15}$.

In patients who have multiple lymphadenopathy deciding which lymph node is to be biopsied may 
be difficult because some of the lymph nodes may not reflect the true diseases process. The actual diagnosis can be delayed or even missed.

FNAB has been shown to be an effective tool in the investigation of multiple lymphadenopathy. Many, if not all, of the enlarged lymph nodes can be sampled at one sitting. If this procedure fails to provide definite diagnosis, the clinician should then proceed to open biopsy ${ }^{16}$.

\section{PURPOSE OF STUDY}

To compare the efficacy of per cutaneous FNA biopsy with open lymph node biopsy.

\section{MATERIAL AND METHODS}

\section{Setting}

Nishtar Hospital, Multan.

\section{Sample size}

50 patients

\section{Duration}

One year

\section{RESULTS}

In this study 50 patients of peripheral lymphadenopathy having various ages ranging from 6-80 years were included. Lymph nodes selected were mainly cervical, axillary, sub-mandibular, supra clavicular, preauricular, inguinal and epitrochlear.

The youngest member in this study was six years old while the oldest was 80 years old.

Maximum number of cases 35(70\%) were between the ages of $11-40$ years and among these $70 \%$ cases maximum number were between the ages of $11-20$ years i.e. 13 cases $(26 \%)$. While the minimum number of cases were between the ages of 61-80 years i.e. 2 cases (4\%) as shown in Fig-1.

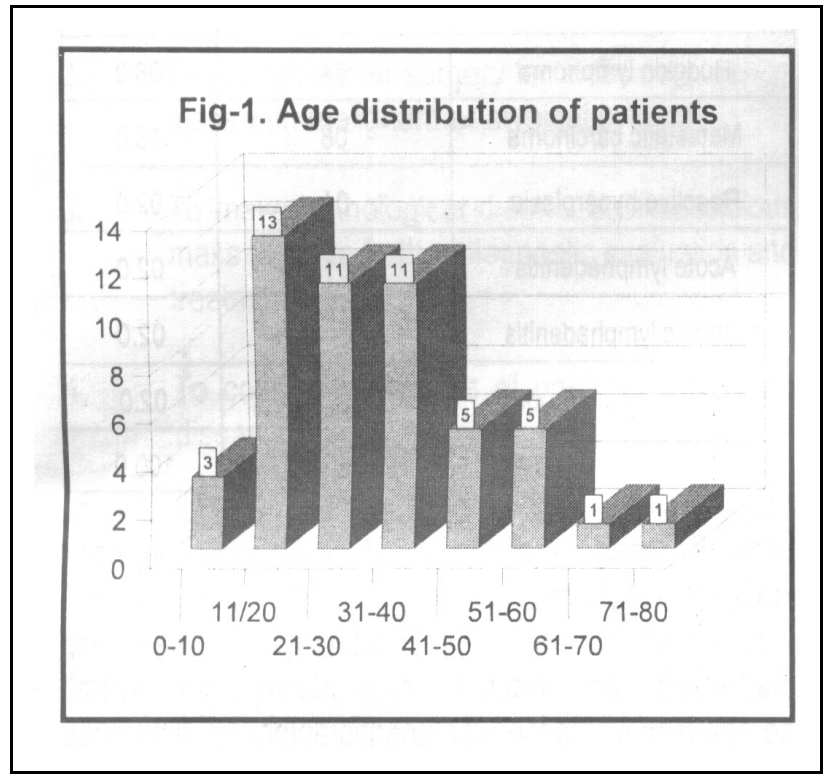

According to the sex distribution tills study showed male predominance i.e. 31 cases $(62 \%)$ were male and $19(38 \%)$ were female. The maximum number of males were between the ages of 11-40 years i.e. 21 cases $(42 \%)$. While the maximum number of female were also between the ages of 11-40 years i.e. 14 cases $(28 \%)$. Among the males, maximum cases were between the ages of 21 and 30 years i.e. $8(16 \%)$ while among females maximum cases were between 11-20 years i.e. 6(12\%). During this procedure adequate specimens were obtained from all cases for cytological interpretation and no complication was observed (Table-1).

Table-1l shows that benign diseases were observed in 30 cases while malignant diseases were observed in 19 cases and an unsatisfactory result was observed in one case. Out of malignant diseases predominance was of lymphoma i.e. 11 cases $(57.89 \%)$ and among the lymphoma, non-Hodgkin lymphoma was observed in 7 cases $(63.63 \%)$ while Hodgkin lymphoma was seen in 4 cases (36.36\%). Metastatic carcinoma of the lymph nodes was seen in 8 cases $(42.10 \%)$. Results of this study show that tuberculosis is still a common disease in our population. Out of 50 cases $27(54 \%)$ were 
diagnosed as tuberculosis on cytological examination with $100 \%$ correlation with biopsy report while lymphoma was diagnosed in $11(22 \%)$ cases out of which non-Hodgkin lymphoma was observed in 7 cases $(14.0 \%)$ while Hodgkin lymphoma was observed in $4(8 \%)$ of cases with $100 \%$ correlation with biopsy report.

\begin{tabular}{|c|c|c|c|c|}
\hline \multicolumn{5}{|c|}{ Table-1. Sex Distribution of Patients } \\
\hline & Male & \% Age & Female & \% Age \\
\hline Age & 01 & 02.0 & 02 & 04.0 \\
\hline $11-20$ & 07 & 14.0 & 06 & 12.0 \\
\hline $21-30$ & 08 & 16.0 & 03 & 06.0 \\
\hline $31-40$ & 06 & 12.0 & 05 & 10.0 \\
\hline $41-50$ & 03 & 06.0 & 02 & 04.0 \\
\hline $51-60$ & 04 & 08.0 & 01 & - \\
\hline $61-70$ & 01 & 02.0 & - & - \\
\hline $71-80$ & 01 & 02.0 & 19 & 38.0 \\
\hline Total & 31 & $62 . .0$ & & - \\
\hline
\end{tabular}

In one of the cases the result was unsatisfactory in which cytological diagnosis of reactive hyperplasia was made while histological diagnosis was non-Hodgkin lymphoma. Reactive hyperplasia and acute and chronic lymphadinitis were observed in 1 case each i.e. 100\% correlation with lymph node biopsy. These results indicate that overall accuracy of FNAC is $98 \%$ (Table-III).

\begin{tabular}{|l|c|c|}
\hline \multicolumn{2}{|c|}{ Table-11. Results of Dine Needle Aspiration Cytology } \\
\hline Parameters & No. of patients & $\%$ Age \\
\hline Adequate specimen & 50 & 100.0 \\
\hline Complication & - & - \\
\hline Unsatisfactory report & 01 & 02.0 \\
\hline Benign diseases & 30 & 60.0 \\
\hline Non-Hodgkin lymphoma & 07 & 14.0 \\
\hline Hodgkin lymphoma & 04 & 08.0 \\
\hline Metastatie carcinoma & 08 & 16 \\
\hline
\end{tabular}

Table-IV shows that the overall accuracy of FNAB cytology was $98 \%$ on comparison with histological diagnosis indicating the usefulness of this technique.

As regard tuberculosis 27 cases, metastatic carcinoma ${ }^{8}$ cases, Hodgkin lymphoma ${ }^{4}$ cases, reactive hyperplasia, acute lymphadenitis, chronic lymphadenitis one case each, $100 \%$ accuracy was found between FNAB-C and histological diagnosis on comparison. 


\begin{tabular}{|l|c|c|}
\hline \multicolumn{2}{|c|}{ Table-Ill. Results of FNAB Cytological Diagnosis } \\
\hline Diagnosis & No. of patients & \%ge \\
\hline Tuberculosis & 27 & 14.0 \\
\hline Non-Hodgkin lymphoma & 07 & 16.0 \\
\hline Hodgkin lymphoma & 04 & 02.0 \\
\hline Metastatic carcinoma & 08 & 02.0 \\
\hline Reactive hyperplasia & 01 & 02.0 \\
\hline Acute lymphadenitis & 01 & 02.0 \\
\hline Chronic lymphadenitis & 01 & 100.0 \\
\hline Unsatisfactory report & 01 & \\
\hline Total & 50 & \\
\hline
\end{tabular}

While 8 cases were diagnosed histologically as non-Hodgkin lymphoma, out of which 7(87.5\%) were non-Hodgkin lymphoma on FNAB cytology and 1 case was diagnosed as reactive hyperplasia. So overall comparison of 1 case was unsatisfactory i.e. difference of diagnosis on FNAB-C and histopathology.(False negative).

Table-IV. Comparison Between FNAB Cytology and Histopathofogical Diagnosis

\begin{tabular}{|c|c|c|c|c|c|c|c|c|c|}
\hline \multirow{3}{*}{$\begin{array}{c}\text { Histopathological } \\
\text { Diagnosis } \\
\text { Tuberculosis }\end{array}$} & \multirow{3}{*}{$\begin{array}{l}\text { No, } \\
27\end{array}$} & \multicolumn{8}{|c|}{ FNAB Cytology } \\
\hline & & TB & Meta & NHL & $\mathrm{HL}$ & $\mathrm{RH}$ & Ac.L & Ch.L & \\
\hline & & 27 & - & - & - & - & - & - & 100,0 \\
\hline NHL & 08 & - & & 07 & - & - & - & & 87,5 \\
\hline $\mathrm{HL}$ & 04 & - & - & - & 04 & - & - & - & 100.0 \\
\hline Metastatic & 08 & - & 08 & - & - & - & - & - & 100.0 \\
\hline RH & 01 & - & - & & & 02 & - & - & 50.0 \\
\hline Ac. L & 01 & - & - & - & - & - & 01 & - & 100.0 \\
\hline Ch. L & 01 & - & - & - & - & - & - & 01 & 100.0 \\
\hline
\end{tabular}




\section{DISCUSSION}

Because of its great convenience, aspiration biopsy of lymph nodes has proved more popular in the recent years. FNAB-C is a sensitive and specific method of diagnosing cases of superficial lymphadenopathy and is indicated in the following situations:

1. To verify the benign nature of a clinically benign ; mass that is to be followed.

2. To prompt earlier surgery for a clinically benign mass with malignant or atypical cytology.

3. To make pathological diagnosis of suspicious mass to guide further diagnostic evaluation and treatment.

4. To confirm metastasis of unknown malignant disease.

5. To follow treated malignant disease with a suspected recurrence.

6. To allow a planned therapeutic approach to malignant disease.

If this method is to be advocated for majority of the patients and to be relied upon in patient management, it just be highly viable with high accuracy, have reasonably high yield i.e. there must be fe,w false negative results and should be quick, safe, cheap, convenient, acceptable to patient, less painful, less traumatic and readily repeatable. In turn, the reliability of this method depends upon the accuracy of needling to enter the. lesion and the accuracy of cytomorphological interpretation.

Although this study has been done comparatively on a small scale but the results are comparable to the studies done on large scales. A lot of work has been done on FNAB-C but there are few studies which concentrate singularly on the lymph nodes.
In this study, out of 50 cases, 27(54\%) were diagnosed as cases of tuberculous lymphadenitis forming a majority group diagnosed not only on FNAB cytology but also on histological examination, indicating that this infectious disease is still a major cause of lymphadenopathy in our population. While second to tuberculous lymphadenitis was lymphoma. Total 11 cases $(22 \%$ of the total cases) were diagnosed as lymphoma out of which 7 cases were of Non-Hodgkin lymphoma which comprises $14 \%$ of total 50 cases and $63.63 \%$ of the total lymphoma cases. Total 4 cases were of Hodgkin lymphoma which comprises $8 \%$ of the total 50 cases and $36.36 \%$ of the total lymphoma cases. So among the lymphoma, it was NHL which was predominant. After the lymphoma at third place was metastatic carcinoma of the lymphnode which comprised of 8 cases i.e. $16 \%$ of the total 50 cases. The rest of the cases were of reactive hyperplasia, one case $(2 \%)$, Acute lymphadenitis, 1 case $(2 \%)$, Chronic lymphadenitis, 1 case $(2 \%)$ and unsatisfactory report was obtained in 1 case $(2 \%)$ in which FNAC was of reactive hyperplasia while the histological diagnosis was NHL. Overall accuracy of this technique was $98 \%$. $100 \%$ results were obtained on comparative study of FNAB cytology and histopathology in tuberculosis of lymph node, metastatic carcinoma, Hodgkin lymphoma. Acute lymphadenitis, Chronic lymphadenitis, while it was $87.5 \%$ in case of NHL and nearly $50 \%$ in cases of reactive hyperplasia and these results closely correlate with the other studies of FNAB cytology. Already various studies have been done on sensitivity and specificity of FNAB cytology. Its sensitivity varies from $77 \%$ to $97.2 \% 15$. In one study 48 histologically proved cases of tuberculous lymphadenitis were subjected to FNAB cytology, 37 patients $(77 \%)$ were detected by this technique15. Our study not only shows comparison in sensitivity but also favour that tuberculosis is still predominant cause of lymph node enlargement. 
A study was done by Dasgupta in 1994 in which FNAB cytology of cervical lymphadenopathy with special reference to tuberculosis was done 17. In this study 188 cases of cervical lymph adenopathy were, studied and it was found that diagnostic accuracy was $84.4 \%$ for

tuberculosis, $84.2 \%$ for caseous necrosis and $73.6 \%$ for epithelioid cells. Acid fast bacilli were observed in $45.6 \%$ of cases. Metastatic carcinoma also yielded high diagnostic accuracy of $98 \%$ showing the significance of FNAB cytology.

In Italy Pilotti et al in 1993 compared the efficacy of FNAB cytology of lymph nodes from suspicious or diagnosed cases of malignancy with excision biopsy. The diagnostic accuracy was $99.1 \%$, while typing accuracy was $96.5 \% 18$. It shows that FNAB cytology may be considered the first step in work up enlargement of superficial lymphadenopathy.

As it has already been mentioned, there are complications and contraindications. One of the advantage was that many, if not all, of the enlarged lymph nodes can be sampled at one sitting. If this procedure fails to provide definite diagnosis, the clinician should then proceed to open biopsy ${ }^{16}$.

In another study results of consecutive series of 1349 fine needle aspiration biopsies from head and neck region of 1193 patients have been reviewed in order to evaluate the efficacy of this method in the diagnosis of tuberculous lymphadenopathy. Of the 108 patients whose FNAB cytology showed granulomatous changes, 68 had subsequent surgery and histologicl confirmation of the cytological appearance. Amongst these 63 were having tuberculous lymphadenopathy; thus specificity of the FNAB cytology was $93 \%$ in diagnosis of tuberculosis related granulomatous lymphadenopathy. Of 1193 patients, 90 patients subsequently had tuberculous lymphadenitis confirmed histologically. Of these 90 patients 69 showed granulomatous changes or AFB, thus the sensitivity of FNAB-C in detecting tuberculous lymphadenopathy was $77 \%$. From this study it is evident that FNAB-C is an efficient way to detect cervical tuberculous lymphadenopathy19. To diagnose sarcoid and tuberculous lymphadenitis special attention has been given to head and neck region $^{20}$.

A study performed in Singapore in 199316 on the use of FNAB-C in patients with multiple lymphadenopathy before open biopsy showed that in two cases of multiple lymphadenopathy open biopsies failed to reveal the true nature of the disease but subsequent fine needle aspiration biopsies did the job, showing that sometimes FNAB is more effective than open lymph node biopsy.

In one study of lymphadenopathy and aspiration biopsy cytology, review of 376 superficial nodes was done and it was found that diagnostic accuracy in cases of metastatic carcinoma and melanoma is nearly $95 \%{ }^{21}$.

Cytological diagnosis by fine needle sampling without aspiration 22 was done and results were compared with those of fine needle aspiration technique in a series of benign and malignant mammory tumour which were subsequently proven histologically. A comparable cellular yield was obtained by both these techniques. With modified technique trauma is reduced and better perception of tumour and its consistency is directly obtained.

While using fine needle aspiration in the diagnosis of cervical lymphadenopathy23, 140 cases were studied and it was found that adequate specimens for cytological interpretation were obtained from $90 \%$. There were no complication and in $96 \%$ of the patients, the fine needle aspiration (FNA.) was diagnostic. This series demonstrates that FNA is a safe, accurate and valuable tool for evaluation of cervical lymphadenopathy. 
In diagnostic assessment of enlarged superficial lymph nodes by FNA24, 285 consecutive out patients with enlarged superficial lymph nodes either clinically suspicious (15 cases) or with a previous diagnosis of a malignant tumour (133 cases) underwent FNA followed by excisional biopsy. Cytologic diagnoses made on direct smear were compared with subsequent histological findings. The comparison demonstrated high rate of conclusive cytologic diagnosis in metastatic malignancies with accuracy rate of $99.1 \%$ and typing accuracy rate of $96.5 \%$. It also showed high rate of conclusive diagnosis in the assessment of high grade NHL and Hodgkin disease with the exception of lymphocytic predominance variant of later. There were significant limitations in the assessment of low grade NHL because of high rate of false negative diagnosis in cases with substantial non-malignant cell component. The results confirmed the diagnostic value of FNA as the first step in work up of patients with nodal enlargement suspicious for malignancy.

The work done on FNAB of lymph nodes inPakistan is limited. Fine needle aspiration cytology (FNAC) on 56 cases of lymphadenopathy was performed at JinnahPostgraduate Medical Centre Karachi during 1990-91. The results of FNAC were compared with histological diagnosisand an accuracy of $95 \%$ was achieved with predominance of tuberculosis and lymphoma ${ }^{25}$.

A few workers performed FNAB on breast lumps and they showed the specificity of $86.7 \%$ while sensitivity of $100 \% 26$. Another study at DHQ Teaching Hospital, Abbottabad during a period of 18 months was carried out in 170 cases to detect the efficacy of fine needle aspiration cytology in evaluation of breast masses. They included 34 malignant and 73 benign lesions. A comparison of histopathology lesion showed a sensitivity of $76.47 \%$, specificity of $100 \%$ and accuracy of $76-$ $64 \%$-with no false positive case27 hence concluding that FNAC could be adopted as diagnostic tool in the evaluation of breast masses and conventional biopsy could be performed on those lesions where FNAC is non conclusive.

Fine needle aspiration cytology of superficial palpable lumps28, including breast lumps, lymphnodes, thyroid goiter was done with slight modification of technique29 300 cases in the department of Pathology and surgery at Chandka Medical College. It showed accuracy of $80-90 \%$. Fine needle aspiration cytology in parotid lumps, on comparison with histopathological diagnosis showed $80 \%$ sensitivity, $94.4 \%$ specificity and $89.3 \%$ diagnostic accuracy ${ }^{30}$.

Evaluation of ultrasound guided FMAC in diagnosis of space occupying lesion of liver was performed in 203 cases at Shaikh Zayed Hospital, Lahore30. Cytological diagnosis showed high degree of sensitivity and specificity with no false positive reports. It was recommended that FNAC can avoid diagnostic laparotomy a major surgical procedure and rate of complications is less with FNAC as compared to liver biopsies.

In fine needle cytology is aspiration necessary. One hundred superficial mass lesions in various parts of the body were sampled by both conventional fine needle aspiration and fine needle without the application of syringe. There was no statistically significant difference between efficacy of the two sampling techniques. So it was suggested that for cytodiagnosis choice of technique can be left to the personal preference of the operator. Recently fine needle sampling has been introduced in certain centres which depends on the principle of capillarity and may thus be called "fine needle capillary" (FNC) sampling ${ }^{3132 ' 33}$.

Ultrasound guided fine needle aspiration biopsy of neck nodes was done and it was found that sensitivity was $98 \%$ and specificity $95 \%$, so it was 
enhanced by this method. With the help of ultrasound many non-palpable neck node can be visualized34'35'36'37. Frable and other authors reported an accuracy of conventional FNAB from $88-98 \% \%^{38^{\prime} 39^{\prime} 40^{\prime} 41^{\prime} 42}$.

So on comparison of all these studies it can be said with great confidence that FNAB cytology is an effective diagnostic tool which is not only time saving but cost saving as well and every patient of superficial lymphadenopathy can be subjected to FNAB cytology. In practice there are clear advantages not only to the patient but to the doctor as well, when compared with open lymph node biopsy

\section{CONCLUSION}

Fine needle aspiration biopsy cytology is a very sensitive, specific and accurate method which provides diagnostic and therapeutic advantages in cases of superficially accessible organs and tissues e.g. lymph nodes, breast, thyroid, skin and also in cases of deep solid enlarged intra-abdominal lymph nodes, space occupying lesions of kidney, liver and pancreas and a few cystic masses. Where the facilities and trained personnel are available this technique is recommended to evaluate the lymphadenopathy before the excisional lymph node biopsy. This is to reduce the number of unnecessary investigations and to guide the clinician on the course of management.

This technique is quick, safe, convenient, relatively painless, time saving, cheap, less traumatic, scarless, acceptable by the patient, can be practiced on an outpatient basis requires no hospital admission and can be attempted at multiple sites. It provides good diagnostic aid prior to the application of radiation in non-operable cases. It helps in assessing the stage of disease, local recurrence in postoperative or post-radiation follow up cases. So it is strongly recommended that it should be used as routine procedure in the initial evaluation of superficial lymphadenopathy.

FNAB-C may also provide material for special studies such as cytochemistry, ultrastructural examination, immunopathology and culture. The procedure is useful in conjunction with radiological techniques such as ultrasonography, CT scan and MRI.

FNAB-C may be performed by clinician, pathologist or radiologist as an outpatient procedure. So along with other advantages it brings a new dimension of cooperation between the medical specialist, cytopathologist and radiologist in this era of emphasis on ambulatory care.

\section{REFERENCES}

1. Thomson P. Thin needle aspiration biopsy. ACTA Cytol 1982; 26: 262-63.

2. Trott PA. Needle aspiration terminology. ACTA Cytol 1983; 27; 83 .

3. Kun M. A new instrument for diagnosis of tumours. Monthly J Med Sci 1847; 7: 853.

4. Grieg EDW, Gray AGH. Note one lymphatic glands in sleeping sickness. Br Med J 1904.1:1252-53.

5. Leyden 00. Ueber infectose pneumonic. Dish Med Uischr 1883; 9: 52-54.

6. Mentier P. Cancer primitif due poumon. Bull SOC Anat (Pais) 1886;11:643.

7. Guthrle CG. Gland Puncture as diagnostic measure. Med J 1921:32:266-69.

8. Forkner CE. Material from lymph nodes of man II, studies on living and fixed cells withdrawn from lymph nodes of man. Arch Int Med 1927,40: 647-61.

9. Dudgeon LS, Patrick CV. A new method for rapid microscopial diagnosis of tumours. Combined use of fine needle aspiration cytologic examination and tuberculin skin test in the diagnosis of cervical tuberculous lymphadenitis. A prospective study. 
Arch Otolaryngeal Heccol Mech Surg 1991; 317: 87-90.

10. Marlin HF, Ellis EB. Biopsy of needle puncture, and aspiration. Am J Surg 1930,92: 69.

11. Martin HE, Ellis EB. Aspiration biopsy. Surg Gynaecol Obstet 1934; 59:578-89.

12. Soderstrom N. Thin needle aspiration biopsy. Acta Cytol I960; 24: 268.

13. Franzen SM, Giertz G, Zajicek J. Cytological diagnosis of prostatic tumours by transrectal aspiration biopsy,

a preliminary report, Br J Ural 1960:32:193-96.

14. Zajicek J. Aspiration biopsy cytology part-1. Cytology of supra diaphragmatic organ monographs in clinical cytology Vol-4, Karyer Basel 1974.

15. Lau SK, Er W1. Kwan S. Combined use of fine needle aspiration cytologic examination and tuberculin skin test in the diagnosis of cervical tuberculous lymphadenitis. A prospective study. Mech Surg 1991; 117:87-90.

16. Lin CT, Loh LE, Pong CM, The use of fine needle aspiration biopsy in patients with multiple lymphadenopalhy before open biopsy. Singapore Med J 1993; 34: 392-94.

17. Dasgupta A, Ghask RN, Poddar AK. FNAC of cervical lymphadenopathy with special reference to i tuberculosis. J Indian Med Assoc 1994; 92 : 4446.

18. Pillotti S, Dipalma S, Alasio L, Diagnostic assessment of enlarged superficial lymph nodes by fine needle aspiration, Acta Cytol 1993; 37: 753-66.

19. Lau SK, Wei W1, C HSV, VCG Engzell. Efficacy of fine needle aspiration cytology in the diagnosis of tuberculous cervical lymphadenopathy. J Laryn \& Otology 1990; 104: 24-27.

20. Lau SK, Wei W1, Hsu C. FNAB of tuberculous cervical lymphadenopathy. Aust N Z J Surg 1988; 58: $947-50$.

21. Kline ST, Kannan V, Kline IK. Lymphadenopathy and aspiration biopsy. Cytology Cancer 1984; 54:1076-81.
22. Zaidela A, ZillhardtP, VoillemotN.Cytoiogica! diagnosis by fine needle sampling without aspiration. Cancer

1987;59:1201-1205.

23. Ashofi S, Carobyon W, Marti J. Fine needle aspiration in the diagnosis of cervical lymphadenopathy. Am J Surg 1986;152:421-23.

24. Pilottl S, Diplama S, ALASIO I/ el al: Diagnostic assessment of enlarged superficial lymph nodes by fine needle aspiration. Acta Cytologica 1993; 85366.

25. Rathi SL, Alam S, Jamal Q. Role of fine needle aspiration cytology (FNAC) in the diagnosis of lymphadenopathy. JCPSP 1996; 269-70.

26. Afridi S, Malik K, Waheed I. Role of fine needle aspiration biopsy and cytology (FNAB-C) in breast lump. JCPSP 1995; 5: 75-77.

27. Bangash AUK, Muhammad GUL. Fine needle aspiration cytology in the diagnosis of breast masses. JCPSP 1994; 98-101.

28. Shaikh SM, Shaikh SA, Rothi SL, Fine needle aspiration cytology of superficial palpable lumps. PJMR1996; 36:

98-99.

29. Frablew J. Needle aspiration of breast cancer.1984.53:671-76.

30. Zafar A, Shafi M, Hassan SH, Fine needle aspiration cytology in parotid lumps. JPMA 1997-.47: 188-90.

31. Frikin F, Chesterman C, Penington D. Tumours of lymphoid tissue, the paraproteinaemias in da-Grucky clinical haematology in Medical Practice 5th ed. Blackwell 1989; 278-317.

32. Sharin M, Dunbar Fionam Becher PJ. Fine needle cytology is aspiration suction necessary? A study of 100 massesin various sites. Acta Cytol I988; 809-13.

33. Santos JEC, Leiman G, Non-aspiration needle cytology. Application of new technique to nodular thyroid' disease. Acta Cytol 1988; 32: 353-56.

34. Jong RJ, Rongen RT, Verwaer D. Ultrasound guided fine needle aspiration biopsy of neck nodes. Arch Otolaryngal Head and Neck Surg 1991; 117, 402-04. 
35. Eichhorn T, Schroeder HG, Glanz H, Histological controlled comparison of palpation and sonography in the diagnosis of cervical lymph node metastasis. Laryngorh intootologie 1987; 66: 266-74.

36. Baatenburg DE, Jong RJ, Rongen RJ. Screening for lymph nodes in the. neck with ultrasound. Clin Otolaryngol I988; 13:5-9.

37. Baatenburg DE, Jong RJ, Rongen RJ. Metastatic neck disease: palpation vs ultrasound examination. Arch Otolaryngol Head Neck Surg 1989; 115: 689. 90.

38. Frable MA, Frable W J: Fine needle aspiration biopsy revisited. Laryngoscope 1982; 92:1414-18.
39. Engzell U, Jacobsson PA, Stgurdson AZ. Aspiration biopsy ofmetastatie carcinoma of lymph nodes in the neck. Acta Otolaryngol 1971; 72:138-47.

40. Meyers DS, Templer J. Aspiration cytology of head and neck masses. Otolaryngology 1978; 86: 376-81.

41. S1 smanls A, Merriam J, Yamaguchi KT. Diagnostic value of fine needle aspiration biopsy in neoplasms of the head and neck. Otolarryngol Head Neck Surg 1981; 89: 62-66.

42. Feldman PS, Kaplan MJ, Johns ME. Fine needle aspiration in squamous cell carcinoma of the head and neck. Arch Otolaryngol 1983; 109: 735-42. 